\title{
BARRIERS AND CHALLENGES PRIVATE HIGHER EDUCATION INSTITUTIONS FACE IN THE MANAGEMENT OF QUALITY ASSURANCE IN SOUTH AFRICA
}

\section{E. Stander}

\author{
Council on Higher Education \\ Pretoria, South Africa \\ e-mail: stander.elmarie@gmail.com
}

\section{Herman}

Law and Policy Studies

University of Pretoria

Pretoria, South Africa

e-mail: chaya.herman@up.ac.za

\section{ABSTRACT}

With globalisation and the rise of the knowledge economy, there has been a worldwide increase in demand for higher education (HE) which has resulted in the proliferation of private higher education institutions (PHEIs). Subsequently, quality assurance (QA) and the management of the QA processes of these institutions have become increasingly important.

QA of PHEIs in South Africa is a contested area. On the one hand, it aims at protecting the public from unscrupulous providers, on the other, the complexity of the QA legislative framework has become a major concern to private providers. This qualitative study focused on the experiences of PHEls in South Africa in the management of QA, while at the same time complying with QA and accreditation processes.

Based on the Octet of Quality in Higher Education, a model adapted from Zaki and Zaki Rashidi (2013); the findings identified three major categories related to the barriers and challenges particular to PHEls as they engage in the management of QA; namely, resources, such as physical and financial resources; capacity development, such as staff roles and responsibilities, academic leadership and development, and research; and programme design, including curriculum design. Key words: private higher education institutions (PHEIs), programme accreditation, quality assurance $(\mathrm{QA})$, management

\section{INTRODUCTION}

In South Africa, the mushrooming of private higher education institutions (PHEIs) is a topical issue, and the quality assurance (QA) of the private higher education (PHE) sector has been at the forefront of higher educational system concerns in an effort to protect the public against 
dubious or illegal HE operators (CHE 2003a; Essack 2015).

In 2002, there were 101 (conditionally) registered PHEIs in South Africa (no statistics on the student enrolment available) (Essack 2015). In 2013, this had increased to 123 institutions with 119941 students enrolled in 2013 (DHET 2013). The predominant racial group of students enrolled in PHEIs in 2013 was the African group, with 65000 students, and second to that almost 27000 white students (DHET 2014). In 2016, there were 125 registered PHEIs in South Africa (DHET 2016b).

All higher education institutions (HEIs) have to accredit their programmes with the Council on Higher Education (CHE); and register each qualification with South African Qualifications Authority (SAQA), which registers and records the qualification in the National Learner Records Database (NLRD). Moreover, before it may recruit or enrol students for its programmes, a PHEI also has to be registered with the Department of Higher Education and Training (DHET) and has to register every programme, which is then added to the institutional registration certificate.

The CHE is responsible for overseeing quality in HE. The CHE's permanent subcommittee, the Higher Education Quality Committee (HEQC), is responsible for the accreditation of all HE programmes (CHE 2001). According to the CHE, programme accreditation refers to the evaluation of HE programmes against the HEQC's nineteen programme accreditation criteria (CHE 2004a).

PHEIs therefore submit their application for programme accreditation to the CHE, where it goes through a lengthy process. This is mainly because of the CHE's peer-review model, in terms of which each programme is subject to various checks before it is sent to a subject evaluator for assessment. A detailed report is subsequently tabled with the Accreditation Committee and then submitted for approval at the HEQC meeting. A programme may accordingly receive any one of the following three outcomes from the HEQC: 'accredited without conditions', 'accredited with conditions' or 'not accredited'. A fourth outcome may be 'deferred' (by the Accreditation Committee), in which case more specific information is required before a decision can be made. If a programme is 'deferred' or 'accredited with conditions', a site visit may be a recommendation. While SAQA's submission for the registration of its qualification forms part of this process, a PHEI has to submit evidence via another process at the DHET as well in order to register with the DHET as a PHEI.

The process of programme accreditation (and re-accreditation) is based on evidence that HEIs submit in order to comply with the CHE's HEQC criteria for programme accreditation (CHE 2004b; Luckett 2006). The programmes submitted for accreditation are evaluated against 
the first nine programme accreditation criteria. However, PHEIs are required to re-accredit their programmes every three to five years (a cycle), whereupon the PHEIs and their programmes have to meet the minimum requirements for the remainder of the nineteen criteria. For the programme re-accreditation process, the CHE's HEQC follows a similar but slightly more complex process which is linked to the registration status of PHEIs at the DHET. Those PHEIs whose programmes have been successfully re-accredited will be re-registered by the DHET for the next cycle; however, a negative outcome from the re-accreditation process may result in deregistration with the DHET (CHE 2004a; 2004b; DHET 2016a). Public universities, on the other hand, follow alternative processes usually linked to funding, such as the Programme Qualification Mix (PQM) clearance at the DHET, which PHEIs do not. Moreover, the process for programme accreditation (and re-accreditation) requires PHEIs to develop and submit over thirty different policies linked to the various criteria for the programme accreditation process in South Africa (CHE 2004b).

The process is even more multifaceted for institutions offering programmes through the distance mode; when designing programmes for the distance mode, as HEIs need to consider further criteria (CHE 2014a).

Despite the efforts of government's main HE stakeholders (e.g. CHE, DHET and SAQA) to regulate and oversee the PHE sector in South Africa, and to develop initiatives for the enhancement of quality in HE, research indicates that many PHEIs still lack effective and actively integrated internal QA procedures and instruments (Cele 2005; CHE 2003a; Essack 2015). In addition, the over-regulation of the PHE sector and the complexity of the QA legislative framework and its processes and criteria seem to be a major concern for the sector (Baumgardt 2013; DHET 2013; Ellis and Steyn 2014). The difficulty that the PHEIs have in managing the various QA process has been acknowledged by the DHET, which maintains that 'a further challenge within the quality assurance system relates to the complexity of the existing registration and quality assurance system for PHEIs, and the sequencing and timing of various processes across the quality assurance bodies’ (DHET 2013, 43).

There is little research on the management of QA in the PHE sector in South Africa. However, the literature that does speak to the topic includes the 2003 HEQC report on The state of private higher education in South Africa (CHE 2003a), Coughlan's unpublished report on PHE in 2011, and the CHE's ten (CHE 2004c) and twenty-year review on HE in South Africa (CHE 2016a). Some of these findings revealed that although the majority of PHEIs had some policies on QA, the policies have not been translated into plans and strategies and the available documentation does not reflect QA arrangements. Various concerns have been highlighted 
about curriculum and programme design, academic staffing and the practices of teaching and learning in the PHE sector. Coughlan (2011) states that 33 per cent of academics in the PHE sector hold only a diploma or less as their highest level of qualification; while the $2016 \mathrm{CHE}$ publication also highlights several quality concerns and deficiencies in the PHE sector. These mostly relate to poor or inadequate teaching and learning strategies and methodologies, a mismatch between academic staff profiles, roles and responsibilities and qualifications; weak programme design; and a lack of responsiveness to social transformation in their programme offerings (CHE 2016a). In most of these and other publications the voice of the PHEIs remains virtually silent.

The purpose of this article is to address some of the gaps in research by exploring the barriers or challenges PHEIs face as they engage in the management of QA experiences, and the perceptions they hold in relation to the topic. The focus is on programme accreditation as this is the first step for PHEIs in securing their registration statuses at both the DHET and SAQA.

The next section presents the methodology for this study, followed by a brief overview of the PHE sector in South Africa. Using Zaki and Zaki Rashidi’s (2013) adapted model, the study identified eight parameters for the management of QA in PHEIs. In terms of the findings, three categories of barriers and challenges are presented in relation to the management of QA for PHEIs in South Africa. A discussion follows in which three themes are identified, highlighting the perceptions of PHEIs as they engage in the management of QA.

\section{METHODOLOGY}

A qualitative exploratory enquiry was deemed most appropriate for the purpose of the study as it mainly focused on the experiences and perceptions of the participants in the PHEIs (Patton 2015).

In relation to size, this study classified PHEIs according to their student enrolment figures, from very small (institution with fewer than 99 students enrolled); small (institution with 100499 students enrolled); medium (institutions with 500-1499 students enrolled); and large (institutions with 1500-4999 students enrolled), to very large (institutions with 5000 and more students enrolled). Institutions were also differentiated in terms of their purpose, being either single-purposed institutions (offering only programmes in one particular subject field, such as marketing or education) or multi-purposed (offering various programmes across many Classification of Education Subject Matter (CESM) categories/subject fields).

Three sets of documents were used to determine which institutions would be sampled. 
These included the Register for Private Higher Education Institutions as published on 24 February 2015, the CHE’s Annual Reports from 2009/2010 to 2013/2014 (CHE 2010; 2011; 2012; 2013b; 2014b) and the Classification of Subject Matter (CESM) (DoE 2009). An examination of these documents revealed that for five consecutive years (between 2009 and 2014), the CHE received the largest number of new applications for programme accreditation in the subject field of Business, Economics and Management Studies (CESM 4). This then became the focus of the investigation.

Within this CESM category, several criteria (such as size of institution, it being based in Gauteng, and consultation with experts in the field) were used to select the sample. Twelve semi-structured interviews, with 13 participants, were conducted at ten PHEIs in Gauteng. The size of the institutions included a combination of small to very large PHEIs. The participants of this study were mainly senior operational and academic staff, and included an equal spread of males and females. All participants were responsible for QA at their respective PHEIs. The interviews were transcribed verbatim, verified with each participant and analysed using ATLAS.Ti 7.5.6.

Although small, the sample was still representative of PHEIs that are accredited to offer CESM 4 programmes in South Africa. However, some limitations should be noted. There are twenty CESM categories (DoE 2007; 2009), and therefore this study automatically excluded PHEIs that offer programmes exclusively in other CESMs. Furthermore, not all the participating institutions offered CESM 4 programmes only. In some cases they offered programmes from four or more CESMs. In addition, only PHEIs based in high-density areas in Gauteng were considered. These limitations may impact on the generalisability of the findings.

\section{CONCEPTUAL FRAMEWORK}

In order to analyse the barriers and challenges experienced by PHEIs in the management of QA in a South African content, an adapted version of the Octet of Quality in Higher Education model by Zaki and Zaki Rashidi (2013) was used.

This model is focused on the institutional environment. It proposes eight parameters that are responsible for driving and/or influencing QA within an HEI. These are (i) institutional design, which refers to both a structural and a contextual dimension; (ii) faculty knowledge, skills and abilities (KSA), referring mainly to the legislative environment, QA management, and teaching and learning strategies, which are seen as the principal agents for inducing quality in education; (iii) institutional leadership, which also includes academic leadership and leadership in terms of development and research; (iv) institutional policies and practice, which 
refers to policy formation and analysis within the HE environment; (v) resources, which denotes financial and physical resources (unlike the Zaki and Zaki Rashidi model which also includes human resources); (vi) student profile (instead of 'learner profile’ as presented by Zaki and Zaki Rashidi’s model), which recognises the student as an important stakeholder in HE and also the QA process; (vii) programme design, which distinguishes between programme design and curriculum design (an amendment to the Zaki and Zaki Rashidi model, which lists this as 'curriculum'); and (viii) open system thinking, which is focused on the creation of learning organisations that are flexible and can adapt to the constantly changing environmental demands, as well the industry.

The conceptual framework provided a basis for understanding and framing the concept of QA management within the PHEIs in the study. It was also used to clarify the findings based on the empirical investigation. The findings highlight three main categories which add to the complexity of the quality assurance process in PHE, especially with regard to the programme accreditation process. These are resources, capacity development and programme design.

\section{Resources}

The data indicated that sufficient, adequate and relevant financial and physical resources are some of the major barriers and/or challenges within the PHE sector and have a significant impact on the quality of HE offerings.

The data also revealed that PHEIs differ greatly in terms of purpose, size, shape and infrastructure. It was found that the larger 'university-type' PHEIs often focus on several disciplines and/or subject fields (multi-purposed institutions) but usually do not have more than four faculties, while the smaller institutions tend to be more specialised in their singular niche disciplines (single-purposed institutions). There seems to be a link between the diversity of the various PHEIs and their ability to manage the QA processes. This is usually influenced by the availability of relevant and sufficient resources.

Furthermore, the study also revealed that size and infrastructure did have an impact on institutions' ability or inability to keep up with the demands of both HE and QA legislative frameworks. Some of the larger university-type PHEIs were owned by, or associated with, renowned public or privately owned enterprises. In the main, such PHEIs did not seem to battle with financial constraints. However, the data revealed that the mainstream of PHEIs do face challenges regarding financial constraints. These usually include the small to medium PHEIs, which make up the majority of PHEIs in South Africa (CHE 2015; Essack 2015).

Since PHEIs rely on student fees, this also poses several other challenges, especially for 
newer or smaller PHEIs. If PHEIs cannot get their programmes accredited, they cannot register the programme with the DHET and obtain a registration certificate, or register their programmes with SAQA on the NLRD, and therefore may not market or enrol students in these programmes. Also, with the continued rise in demand for PHE in South Africa, there seems to be an overload of regulation in both QA and HE legislation, especially from the three main stakeholders in HE - the CHE, the DHET and SAQA - in an attempt to limit or expunge poor quality providers. New or recently registered providers (provisionally registered) are also met with greater vigilance from all state authorities. Consequently, only financially stable institutions can survive:

[The] cost of compliance is so high, the stronger people are going to survive ... it is just too expensive ... I don't know how [the small providers] survive (Participant 8:6).

The timing and length of the QA processes linked to getting a programme accredited by the CHE, registering with the DHET, obtaining a registration certificate, and registering the qualification with SAQA also present several challenges for providers:

The process is far too long, the cycle it's too long [and often you get the outcomes] too late for the next academic year ... I'm losing ... millions in income. [The] whole process [with the CHE, DHET and SAQA] is almost stretched to three years (Participant 5:12).

While PHEIs are faced with more pressure to comply with HE and QA legislation, the high costs related to these processes often fail to make 'business sense' (Cele 2005).

The effectiveness of these QA processes is often seen as insufficient, especially when it comes to the evaluation of physical and financial resources. Both the CHE and the DHET mainly use a paper-based evaluation of these resources. According to the data obtained there would also seem to be inequality in the provisioning of HE programme offerings. For instance, there appears to be a handful of PHEIs that are accredited to offer the same qualification (same designator and qualifier), each with its own set of infrastructure, resources and support structures. One PHEI may offer a particular programme, perhaps in contact mode, and have more than adequately qualified lecturers, physical and online library facilities, Wi-Fi connection on campus, upmarket lecture rooms, a cafeteria, a well-developed student-support database and sufficient support staff in place. In contrast, another institution offering the same type of qualification may have inferior quality staff, resources and facilities. While the first institution may charge double in tuition fees what public universities charge, the latter will offer the same qualification at a fraction of the tuition fees public universities charge. Consequently, the credibility of HE academic programmes (qualifications) offered by some PHEIs is often 
questioned.

In addition, there is a perception that the QA process does not distinguish between the different institutions. One reason for this may be the HEQC's focus on the programme for accreditation, rather than on both the institution and the programme. Most participants recommended that the entire accreditation process should change and should include both programme and institutional accreditation. It was also suggested that the processes linked to DHET registration, which consider sites of delivery, facilities, budgets/financial statements and business plans, are inadequate. This seems to be a concern for some credible PHEIs, as explained by this participant:

[The CHE] have to do both, [programme accreditation and institutional accreditation]. You cannot divorce the programme from the institution, because you can have a good department, with a good programme, but there can also be a very bad department in that same institution, especially with multi-campuses ... You can have a very good programme that is accredited in principle ..., but in Durban it works and in Nelspruit it doesn't work (Participant 4:8).

Most PHEIs are self-funded, and therefore have limited resources available. Consequently, it seems that they often struggle to supply the basic, relevant and adequate resources needed to offer quality HE programmes (Welch et al. 2004; CHE 2016a). The costs involved in facilities, electronic and physical library holdings, Wi-Fi, Management Information Systems (MIS), employing senior academics, and the like, are all factors that drain resources even before PHEIs have an accredited programme or start offering it. In addition, external councils, professional bodies and departments often require PHEIs to provide evidence of having invested in all the resources before they have certainty about the outcome of many external QA processes. It is ‘almost a “chicken-[before-the]-egg”-situation’ (Participant 4:10). The HEQC’s process of programme accreditation is one such example.

[The HEQC] would defer a programme, for instance, [because] you don't have staff, but who's going to employ staff until the programme is accredited ... Of course I don't have staff. I have somebody who can coordinate the programme, but I'm not employing lecturers until I got the programme [accredited] (Participant 8:7).

\section{Capacity development}

QA processes, like those of programme accreditation, are usually assessed in 'good faith' on promises from the institutions, and evaluated at a particular time when the applications are submitted. In a space where resources are limited, capacity development is often problematic, and this may have a negative effect on various QA processes.

Such QA processes also often evaluate the PHEI’s programmes in the light of their link to the workplace and their relevance to servicing students who might never have been able to 
attend a public university and obtain a degree (DHET 2013; Essack 2015). The data revealed that in some instances the smaller, niche (single-purposed) PHEIs appear to have become a benchmark in their industries:

There [are these] amazing places that offer very niche or specialist programmes ... [Those] times when you looked down at other institutions and what they offer are now also basically over. I think they all play a role (Participant 11:14).

Such niche and specialised PHEIs often do not intend to expand to other disciplines. Institutional capacity is therefore built around the functions of offering these disciplines. For example, top quality staff and resources are acquired to gain advantage and a good rapport in the industry. However, staff are often only subject/industry specialists and do not always have sound pedagogical knowledge. So, while they might be brilliant film-makers, chefs, economists or CEOs, they do not have the capacity to assure the quality of HE programmes. The jargon and best practices related to QA and HE are often too complex, and this complexity and various process-based challenges are some of the most common barriers for South African PHEIs:

[There] are many things we don't understand. We are not educationalists ... We all come from the business sector. We sometimes don't even know the words the CHE use (Participant 1:14).

Medium to larger university-type (multi-purposed) PHEIs, however, also seem to have gained favour in the industry, mainly with distance education programmes which are designed to accommodate working adults:

Our student's average age is probably thirty-six. ... The majority of our business is done through distance learning, and are mature students (Participant 3:3).

In terms of capacity, medium-sized PHEIs seem generally more stable than the smaller providers. They appear to have a greater and more stable staff complement, they often have capacity development policies and structures to support their growth, and have usually been established for more than a decade, during which time they have matured and worked through various quality concerns:

[We] are [now] over that feeling, that we just need the policies for accreditation at the CHE. We realise, that if you don’t have it in place, you are jeopardizing the institution (Participant 11:16).

Regardless of their size and purpose, it seems that customer service is a major focus for most profit-driven PHEIs, which often build the larger part of their capacity around those services. ‘Customer service is priority’ (Participant 9:14).

However, in the majority of PHEIs, the lack of internal capacity, specifically with regard 
to the academic programme and the assurance of the quality of the academic programme, has been identified as a major concern by various participants in this study. Some of these concerns are highlighted below.

The deflation of key roles and responsibilities within PHEIs is one of the major concerns. Participants indicated that the majority of PHEIs do not have clearly defined roles and responsibilities and very often one person assumes multiple roles.

[In] most institutions, you have the CEO, who's also the registrar, who's also a lecturer, and also the manager (Participant 3:7).

PHEIs often start with such a model (where everyone is multi-tasking) in the spirit of 'saving costs', but this continues to be the norm. In addition, most PHEIs battle to find suitable academic staff. This refers to the relevance of their qualifications, expertise and experience. This is often linked to the lack of high packaged pay-scales and the prestige often associated with academics at public universities, which academics at PHEIs do not get.

It further seems common practice for PHEIs to make use of part-time staff who are actively pursuing careers in specific industries. For instance, they will contract an auditor to teach auditing for a term. However, the lack of certain educational knowledge, skills and abilities may result in serious flaws in their teaching and learning functions. This can also have a negative effect on the management of both the academic programme and the assurance of the quality of the programme as a whole. Fundamental good practices that are well known and respected in the global HE community may quite often be ignored (CHE 2016b; 2016c; Welch et al. 2004).

With regard to QA, the level of experience and exposure to various QA processes, such as programme accreditation, has been identified as a significant advantage for most of the people involved in QA at PHEIs. The lack thereof has a negative impact on PHEIs, specifically on new institutions.

[The] split is [between] people who've been [involved in the processes of programme accreditation] for years, and people who haven't been doing it for years. I think there needs to be far better induction for new providers (Participant 8:4).

While it has also been found that the leadership in charge of the QA processes and the creation of a culture of QA should ideally be vested in full-time staff and academics, it appears as if the PHE sector generally contracts part-time staff, and outsources responsibility for key functions and designations to consultants, such as the QA director, or academic head of PHEIs. PHEIs also commonly appoint consultants to manage the accreditation of their programmes. 
Institutions appoint consultants to do the wrong thing. [If you] appoint consultants to do your accreditation, [you] don't deserve that accreditation (Participant 3:27).

While outsourcing and part-time lecturing seem to be an acceptable and even cost-effective model for the PHE sector, it is not considered good practice and has implications for the quality of the programmes:

[The] ownership of the programme has to lie with full-time staff - permanent employees ... All [the] key expertise, and subject matter expert knowledge has to lie within the full-time permanent staff (Participant 7:7).

With regard to academic staff, only a very small group of institutions has chosen to appoint senior academic staff, especially retired senior lecturers and professors. In these cases, the PHEIs are mainly focused on offering postgraduate programmes such as postgraduate diplomas, masters and doctoral degrees.

[Ninety] percent of our lecturers are ex-[university] lecturers, senior lecturers and professors (Participant 1:1-2).

Programme accreditation criteria also encourage PHEIs to work toward a diverse and equitable staff complement. This appears to be a difficult task:

... as difficult as it is to find an auditor who wants to teach, it's even more difficult to find [an African] auditor who wants to teach (Participant 3:4).

However, it has been noted that the majority of PHEIs choose to employ younger, yet qualified, staff. While a lower pay-scale is the main reason for this, another reason seems to be linked to the enthusiasm and energy that young academics bring to an institution. This is perceived to have a positive influence on the quality of the HE product and its services holistically.

However, this also has a negative impact on the quality of the HE programme offerings, as younger faculty often lacks academic leadership within their institutions. Academic leadership includes 'knowledge development, knowledge production, knowledge dissemination, in creating a sustainable and equitable HE sector through innovation, promoting academic excellence and the collaborative pursuit of knowledge' (Engelbrecht 2015).

In addition, the lack of academic leadership in the field of research has also been identified as a major challenge. Many of the participants explained that their institutions did not have the capacity to produce research outputs. Instead, they encouraged their staff to pursue postgraduate studies - either offering free or discounted tuition, or funding their academic staff to pursue their studies at various reputable public HEIs. The concern here points to the lack of academic 
research capacity and leadership within the institutions to guide the development of younger researchers. The exclusion of the PHE sector from public funds also greatly influences the research output of the sector. Although research has shown that relevant and current research is being done within the PHE sector (DHET 2013), it appears that the sector is not properly represented in the accredited journals in South Africa (Baumgardt 2013; CHE 2016a).

[A] lot of private providers battle with research, and the reason [is because] their people in academic leadership positions are not researchers ... Most just go off and do their PhDs, but that's your own research. It's not institutional research (Participant 3:7).

The challenge of capacity development also plays an important part in the development of programme design.

\section{Programme design and the programme accreditation criteria}

The concept of programme design refers to the complete design of the programme (including the curriculum). Both programme and curriculum design have been identified as separate areas of concern by this study (CHE 2014b), and a flawed programme design has been identified as one of the most common reasons for institutions not obtaining successful programme accreditation (CHE 2014b). The data further confirmed that one of the most prominent problem areas linked to programme design seemed to be the lack of deeply vested knowledge and skills of HE curriculum design and development.

I also think that curriculum development skills, particularly in small private provider structures, are often not available. [It is] a somewhat technical discourse in itself. They often need to subcontract those skills, perhaps while they build their own capacity around that ... (Participant 7:7).

This includes a lack of understanding of the different teaching and learning strategies linked to each mode of provisioning (or delivery), and the accurate use of ICTs in specific disciplines within the HE sphere. Mode of delivery for HE programmes seems to be another challenge. Although the DHET (according to its New Funding Framework (NFF) (DoE 2003)) and the CHE recognise only contact or distance legislatively, it appears as if most institutions follow a 'blended' mode of delivery.

[We have] a kind of blurred relationship ... between the distance and contact programmes. ... [We] call it ... blended mode (Participant 12:5).

It further seems as if a large majority of PHEIs do not understand how to implement their programmes via the different modes of delivery and do not understand the fundamental differences in teaching and learning strategies related to each mode of delivery. 
Some [PHEIs] ... thought: 'Great, we can take our contact learning qualification and we can just deliver it to our students via the post' .... You cannot assume that if you are a good contact provider, that you will be a good distance provider. This is a completely different pedagogy and paradigms .... A lot of people [also] think it's cheaper to run a distance programme .... Our experience is that ... it's more difficult and more expensive (Participant 3:6).

It further appears that the benchmarking of curricula, and institutional structures and practices that support and form part of a programme, has been suggested by a few participants as a valuable QA evaluation approach to programme design. The CHE defines benchmarking as 'a process of comparing programmes or a course in an institution against similar ones in other institutions, to assess their parity in terms of quality, standards, levels and other specified features’ (CHE 2016c, vi)

Benchmarking can also assist PHEIs to stay competitive and current, and requires 'open system thinking' (Zaki and Zaki Rashidi 2013). The data revealed that some benchmarking approaches mentioned by participants included the formation of industry-specific interest groups, especially for academic research publications, the use of standard textbooks used in public universities or benchmarking curriculum standards with international standards in a specific field.

However, generally, it was suggested that even though the SAQA qualifications submission requires both local and international comparability, it comprises merely a desktop evaluation by evaluators. In addition, it has also been perceived that often specialised PHEIs benchmark themselves against similar-type institutions and their benchmarking activities are mainly limited to the curriculum outline. Consequently, they often benchmark themselves with institutions that follow similar curriculum designs, teaching and learning models or approaches, or pedagogical beliefs within their fields, and therefore may exclude examples of good practices within the sector. For instance, they may benchmark themselves against institutions offering a business programme that has been designed around one particular theory and are offering it in a particular way that is not always suited to HE but rather to the vocational sector. This often occurs with curricula promoted by international professional associations, which might contradict what the aim of South African HE aspires to (CHE 2013c) and is difficult to map on the HEQSF (CHE 2013d):

[Our] programme is unique in Africa, and even in the world. There are some countries that do follow this approach ... [This approach is] an international curriculum from the highest professional organisation in the world [and are from an international professional association] (Participant 1:3).

It does seem as if most PHEIs do consult the industry to inform their curriculum when designing 
their programmes. However, it appears that their focus often leans towards knowledge creation for their clients (often companies), rather than new knowledge creation for the sector internationally. While these companies do form part of the industry, the knowledge obtained is kept private:

We will never put [our student's dissertations] on [our] website. ... [Our] students ... have [to] signed a confidentiality clause which will have a great impact on their institutions if it will get published. [Employers] pay for their studies, [and therefore], the research stays confidential (Participant 1:5).

Qualifications are therefore developed mainly around their clients' (companies') need for staff development, or SETA-funded learnerships, which are often referred to as 'applied' HE qualifications. PHEIs thus design and incorporate bespoke case studies and research projects that are focused on their clients' company or industry.

[We] also force our students to do research within their own company. It is a work-context dissertation, in order to create new knowledge for their [workplace] (Participant 1:4).

\section{DISCUSSION}

From the findings, three themes were identified which highlight the perceptions of PHEIs as they engage in the management of $\mathrm{QA}$ and accreditation processes. These include the complexity of the QA processes in $\mathrm{HE}$; the feeling of being victimised by the main QA processes in HE and their structures; and distrust.

\section{Complexity of the QA processes in HE}

Generally, the complexity of the various QA processes of the CHE, DHET and SAQA has been highlighted. It was perceived that these processes are often seen as technocratic and their criteria and procedures outdated.

For example, in relation to programme accreditation, several process-related concerns and perceptions relating to resources have already been highlighted. In addition, another concern is the turnaround time of the processes linked to programme accreditation. The outcome and timing of the programme accreditation (and re-accreditation) process has a great influence on the survival or continued existence of many PHEIs. Also, many PHEIs perceive the QA processes in HE to be unresponsive to the needs in industry, which is the cause of a great deal of frustration on the PHEIs' part:

[The QA of processes in HE are] is not very responsive in the sense, to meet the needs out there ... [It] is focussing on young students for entering the system, [and] not thinking that there are lots of corporates whose people also need formal qualification ... and they don't expect a long process 
[to get a programme accredited] (Participant 12:9).

For many PHEIs, the programme accreditation (and re-accreditation) process has become onerous, being expensive and complex, and is perceived as very uncertain: '[What the HEQC has,] is a very complex kind of process, which is actually unmanageable' (Participant 8:3).

\section{Feeling victimised}

Generally, PHEIs also feel victimised by the entire system. Often they feel as if policies and regulation favour the public universities and that the PHE sector is over-regulated: '[Of] course there's far higher vigilance on the private sector than in the public sector ...' (Participant 8:2).

There are also different expectancies and requirements from public universities than from PHEIs, as public universities are not required to comply with all of the criteria. While the CHE and DHET have very good reason for this, two differences between the requirements for public and private HEIs are highlighted:

Firstly, PHEIs often feel that the quality of their programmes is more rigorously measured and evaluated than that of public universities (Baumgardt 2013; Ellis and Steyn 2014) and that the system has uneven expectations. Public universities are exempt from criteria 3, 4, 7 and 8 in the programme accreditation process. While it may be perceived as if government's HE stakeholders favour public universities, the CHE for instance assumes that the various institutional and DHET processes that led up to PQM clearance have already dealt with various matters highlighted by criteria 3, 4, 7 and 8 (Nieuwenhuis 2016). In addition, public universities are subject to processes such as national reviews, audits and the quality enhancement project (QEP), while the involvement of PHEI in the QEP is voluntary.

Secondly, PHEIs are required to pay for all programme accreditation applications. This works on a cost recovery basis. Public universities, on the other hand, are funded from the same source as the CHE and therefore do not pay for any of these processes.

\section{Distrust}

Interestingly, it seems to be the opinion of most participants from the larger reputable institutions that the 'time of the "fly-by-nights" is over' (Participant 5:16), but they nevertheless often feel labelled and treated as 'dubious operators', as explained by this participant from a large PHEI, saying:

At the moment, all hundred and something private institutions, are all evaluated and treated the same. We are seen and treated the same [by authorities] as the 'Aroma Therapy College' in someone's backyard (Participant 4:11). 
PHEIs also felt they were often distrusted by authorities, stating:

[Don't] punish the legitimate businesses by making it too difficult for us who wants to be legal and legitimate. ... It is like punishing the whole class, because one little boy is unruly ... (Participant 5:16).

\section{CONCLUSION}

Using the conceptual framework adapted from Zaki and Zaki Rashidi (2013), this study identified three categories of major barriers and challenges: resources, capacity development and programme design. All three proved to have a significant influence on the quality of the HE provisioning within the sample selected for this study, while programme design was found to be slightly more important than the rest. For instance, if a PHEI does not have an accredited programme, it cannot be registered with the DHET as a PHEI. This also seems to have a significant impact on all the other parameters in this conceptual framework.

Funding in terms of PHE therefore refers mainly to self-generated funding. While the findings concluded that not all PHEIs battle with financial and physical recourses, the majority of participants from respective PHEIs lack such resources. With the exception of some religious colleges funded by donors, the larger PHEIs seem mainly driven by the profit imperative, and not by patriotism or any other higher duty (CHE 2016a; Nieuwenhuis 2016).

A lack of capacity development in the PHE sector has also been identified as another barrier. While outsourcing and the use of consultants has become the norm, the absence of sound knowledge of QA and HE legislation and practices seems evident. This study also identified programme accreditation as a form of external QA and its criteria have been discussed (CHE 2004a). The CHE expects all institutions to be responsible for their own internal QA and therefore provide evidence of their own capacity to offer quality HE offerings. The management of internal QA therefore directly influences external QA processes.

In addition, teaching and learning strategies, including subject-specific knowledge and pedagogical content knowledge, seemed problematic. With a few exceptions, programme (and curriculum) design competencies appear to be a general concern in the PHE sector. This includes sound benchmarking practices.

While the management of QA in HE globally remains in flux, PHEIs in South Africa seem to battle constantly with the balance between the business imperative, the academic nature of their business and the services they provide.

Lastly, three themes were identified for discussion on the perception of PHEIs with regard to the management of QA. The first refers to the complexity of the QA processes. In 2015, when this study was done, QA processes were already perceived by PHEIs as complex and 
unmanageable. Since then, additional policies and legislation have been passed, which continue to put more pressure on PHEIs. Some of these include the DHET's Regulation for PHEIs, as amended in March 2016 (DHET 2016a); the CHE's Policies on the Recognition of prior learning, credit accumulation and transfer, and assessment in higher education (CHE 2016b); A good practice guide for the quality management of short courses offered outside of the higher education qualifications sub-framework (CHE 2016c), to name but a few. The third refers to the feeling of victimisation which is generally shared by PHEIs. Thirdly, distrust. Most PHEIs perceived themselves as being distrusted by authorities. However, Samuels (2016) states that, since its inception up to 2016, SAQA has found that in South Africa 32 per cent of all the degrees and 13 per cent of all the diplomas it has evaluated and confirmed have been forged. In 2016, the CHE also drastically increased its total of site visits, as a tool for verifying the quality of programmes; and the DHET also now aims to register every learning support centre, which has huge implications for all providers.

While numerous quality deficiencies continue to characterise the entire PHE sector, it appears as if mere (over-) regulation of the PHEIs will not be the answer. The state and all its stakeholders are being called on to do significantly more capacity development within the PHE sector in an attempt to assure equity in the provisioning of HE across the sector. This is important and speaks to the overall increased demand for quality HE in South Africa. In addition, more quantitative studies are needed within the PHE sector, as there is a lack of audited and reliable data representing the nature of the PHE sector (CHE 2016a).

\section{REFERENCES}

Baumgardt, J. 2013. Quality assurance challenges for private providers in post-school education and training in South Africa. Doctor of Education dissertation. University of South Africa, Pretoria.

Cele, N. 2005. The consequences of the absence of a 'norms and standards' legislative framework for institutional accreditation in private higher education: A disconnect between policy, expectations and quality assurance practice. South African Journal of Higher Education 19(3): 188-202.

CHE see Council of Higher Education.

Coughlan, F. 2011. Private higher education 2011. Unpublished report. In Council on Higher Education (CHE). (2016). South African higher education reviewed: Two decades of democracy. Pretoria: CHE.

Council on Higher Education. 2001. Founding document. Pretoria: CHE.

Council on Higher Education. 2003a. Higher Education Monitor. The state of private higher education in South Africa. No. 1, June. Pretoria: CHE.

Council on Higher Education. 2004a. Framework for programme accreditation. Pretoria: CHE.

Council on Higher Education. 2004b. Criteria for programme accreditation. Pretoria: CHE.

Council on Higher Education. 2004c. South African higher education in the first decade of democracy. Pretoria: CHE.

Council on Higher Education. 2010. Annual Report 2009-2010. Pretoria: CHE. 
Council on Higher Education. 2011. Annual Report 2010-2011. Pretoria: CHE.

Council on Higher Education. 2012. Annual Report 2011-2012. Pretoria: CHE.

Council on Higher Education. 2013a. Annual Report 2012-2013. Pretoria: CHE.

Council on Higher Education. 2013b. A proposal for undergraduate curriculum reform in South Africa: The case for a flexible curriculum structure. Pretoria: CHE.

Council on Higher Education. 2013c. The aims of higher education: Kagisano Number 9, March. Pretoria: CHE.

Council on Higher Education. 2013d. Higher Education Qualifications Sub-Framework (HEQSF). Pretoria: CHE.

Council on Higher Education. 2014a. Distance higher education programmes in a digital era: Good practice guide. Pretoria: CHE and SAIDE.

Council on Higher Education. 2014b. Annual Report 2013-2014. Pretoria: CHE.

Council on Higher Education. 2015. Vital stats. Public higher education 2013. Pretoria: CHE.

Council on Higher Education. 2016a. South African higher education reviewed: Two decades of democracy. Pretoria: CHE.

Council on Higher Education. 2016b. Policies on the recognition of prior learning, credit accumulation and transfer, and assessment in higher education. August. Pretoria: CHE

Council on Higher Education. 2016c. A good practice guide for the quality management of short courses offered outside of the higher education qualifications sub-framework. Pretoria: CHE.

Department of Education. 2003. The new funding framework for higher education institutions, in terms of the Higher Education Act, No. 101 of 1997. Government Gazette (No. 1791), 9 December.

Department of Education. 2007. CESM: Classification of Educational Subject Matter. Pretoria.

Department of Education. 2009. Amended CESMs: Classification of Educational Subject Matter (as published on 19 January 2009). Pretoria: DoE.

Department of Higher Education and Training. 2013. White Paper for post-school education and training: Building and expanded, effective and integrated post-school system (As approved by Cabinet on 20 November 2013). Pretoria: DHET .

Department of Higher Education and Training. 2014. Statistics on Post-School Education and Training in South Africa: 2012. Pretoria: DHET.

Department of Higher Education and Training. 2016a. Higher Education Act 101 of 1997: Regulations for the registration of private higher education institutions, published 31 March 2016. Government Gazette (No. 39880), Notice No. 383. Pretoria: Government Printers.

Department of Higher Education and Training. 2016b. Register of private higher education institutions (Published 25 February 2016). Pretoria: DHET.

DHET see Department of Higher Education and Training.

DoE see Department of Education.

Ellis, M. E. and G. M. Steyn. 2014. Manager's perceptions of regulatry legislation of private higher education in South Africa. International Educatin Science 6(3): 445-458.

Engelbrecht, M. 2015. The art of shape shifting: Academic leaders in time of change. Paper presented at the 26h Internaional Council for Open an Distance Education (ICDE) World Conference: Growing capacities for sustainable distance e-learning provision. Sun City, South Africa, 13-16 October 2015.

Essack, S. 2015. Private higher education institutions. Quality Assurance Workshop: Private Higher Education Institutions (of the Council on Higher Education), presented on 8 October 2015. Birchwood, Johannesburg: Council on Higher Education (CHE).

Luckett, K. M. 2006. The quality assurance of teaching and learning in higher education in South Africa: An analysis of national policy development and stakeholder response. Doctoral thesis. University 
of Stellenbosch.

Nieuwenhuis, J. 2016. The history of higher education quality assurance processes in South Africa. Informal interview, 2 August, Pretoria.

Patton, M. 2015. Qualitative research and evaluation methods. 4 ed. London: Sage Publications.

Samuels, J. 2016. Key initiatives impacting on quality assurance in the SADC Region. SAQA. $3^{\text {rd }}$ SAQA Conference. 19-21 October. CHE: Pretoria.

Welch, T., Y. Reed and NADEOSA. 2004. Designing and delivering distance education: Quality criteria and case study from South Africa. Braamfontein: NADEOSA.

Zaki, S. and M. Zaki Rashidi. 2013. Parameters of quality in higher education: A theoretical framework. International Journal of Social Science and Eductation 3(4): 1098-1105. 